10. Montero $E$, L ucena $F$, Gutiérrez F, López I. Tratamiento del tromboembolismo pulmonar con heparina de baj o peso molecular. An Med Interna 1995; 12: 515-516.

\section{Trombocitopenia severa asociada a factor estimulante de las colonias de granulocitos y macrófagos (rHU-GM-CSF)}

\section{Sr. Director:}

Se presenta un caso de trombocitopenia en un paciente afecto de SIDA en tratamiento con factor recombinante humano estimulante de colonias granulocíticas y macr ofágicas (rHu GM-CSF).

Se trata de un paciente infectado por el HIV diagnosticado en 1989 que ha presentado como infecciones oportunistas candidiasis oral y neumonia por P neumocistis carinii.

En el momento actual la cifra de CD 4 era de $100 \mathrm{c} / \mu \mathrm{L}$ y no seguía ningún tratamiento retroviral. El motivo del actual ingreso fue un cuadro de fiebre diarrea y dolor abdominal en fosa ilíaca derecha. La fibrocolonoscopia mostró un absceso pericolónico a nivel del ciego. En las muestras de microbiología del la biopsia de ciego y en heces se aisló $M$. fortuitum, por lo que se inició tratamiento con amicacina (500 mg/12 h), doxicilina (100 mg/12h) y ciprofloxacina (750 mg/12 h) sin mejoría clínica. Se realizó una limpieza y drenaje quirúrgico del absceso, pero el paciente permanecía febril y con importante afectación del estado general. Se cambió el tratamiento antibiótico por amoxicilina-clavulánico (1g-125 mg/8 h), roxitromicina (150 mg/12 h), amicacina (500 $\mathrm{mg} / 12 \mathrm{~h})$ y añadió $\mathrm{GM}-\mathrm{CSF}(300 \mu \mathrm{g} / 24$ h) con intención de estimular la función macr ofágica. Antes de la introducción del GM-CSF el recuento plaquetario era de $15 \times 10^{\circ} / \mathrm{L}$, leucocitos $4,1 \times 10^{\circ} / \mathrm{L}$ y $\mathrm{Hb} 11 \mathrm{~g} / \mathrm{dL}$. A los 6 días del inicio del GM-CSF el recuento plaquetario bajó a $11 \times 10 / \mathrm{L}$ y la $\mathrm{Hb}$ descendió a 7,2 g/L, la cifra de leucocitos ascendió a 7,5 x $10^{\circ} / \mathrm{L}$. EI paciente recibía entonces tratamiento con amoxicilina-clavulánico, roxitomicina y amicacina a las dosis mencionadas además de tratamiento retroviral con ritonavir $(600 \mathrm{mg} / 12 \mathrm{~h})$, D 4T (40 mg/12 h) y 3T C $(0,75 \mathrm{mg} / 12 \mathrm{~h})$. Como complicación el paciente presentó gingivorragías espontáneas y hematomas en distintas localizaciones, por lo que se discontinuó todo el tratamiento tanto antibiótico como retroviral. Se realizó un aspirado de médula ósea que mostró aumento de las series megacariocítica y granulocítica-limfoplasmática. Trece días después de la suspensión del tratamiento el recuento plaquetario ascendió hasta $283 \times 10^{9} / \mathrm{L}$.

Ninguno de los fár macos retrovirales o antibióticos que en aquel momento estaban siendo administrados se han asociado a trombocitopenia. Cualquier otra razón que explicase la trombocitopenia fue descartada. T ras la recuperación hematológica se reintrodujo el tratamiento retroviral y antibiótico sin cambios en los recuentos plaquetarios posteriores.

La fiebre, dolor óseo y mal estado general han sido descritos como efectos secundarios comunes asociados al GMCSF. La trombocitopenia es un efecto secundario poco frecuente que ni siquiera ha sido mencionado en una revisión reciente hecha por Barbaro et al (1). R ecientemente se ha descrito un caso de trombocitopenia en relación a la administración de GM-CSF en la que la trombocitopenia se atribuye a depleción de progenitores a nivel medular (2), sin embargo la falta de aspirado de médula ósea en este caso no permite mencionar esta hipótesis.

El caso aquí presentado trata de un episodio de trombocitopenia en relación con la administración de GM-CSF. Tras la suspensión del tratamiento el recuento plaquetario ascendió hasta niveles normales, oras causas de trombocitopenia fuer on excluidas. La reintroducción del tratamiento, excepto del GM-CSF, que estaba recibiendo el paciente cuanto se manifestó la trombocitopenia no modificó posterior mente el recuento plaquetario, por lo se puede concluir que la administración de GMCSF fue la causa de la trombocitopenia.En este caso el resultado del aspirado de médula ósea que mostró un aumento de megacariocitos apoya la teoria de que es una causa periférica y no un mecanismo central, la causa de la trombopenia asociada a la administración de GM-CSF.

\section{Tortajada, F. García, J. M. Miró, J. M. Gatell}

Servicio de Infecciones. Hospital Clínico. Barcelona.

1. Barbaro G, Di Lorenzo G, Grisorio B, Soldini M, Barbarini G. Effect of recombinant human granulocyte-macrophage colony-stimulating factor on HIV-related leukopenia: a randomized, controlled clinical study. AIDS 1997; 12: 1453-1461.

2. Holtzer CD, Stanley HD, Jacobson MA. Severe reversible thrombocytopenia cause by recombinant human granulocyte colony-stimulating factor in an AIDS patient reciving chronic ganciclovir therapy. AIDS 1997; 11: 1405-6.
Neumonía por P neumocystis carinii en pacientes con infección por el virus de inmunodeficiencia humana. R evisión de 70 casos

\section{Sr Director:}

EI Pneumocystis carinii fue descubierto en 1909 por Chagas. En la década de 1960, el P. carinii fue implicado ampliamente como una causa importante de neumonía en los huéspedes inmunocomprometidos. En la década de 1980 se asistió a un aumento dramático en la incidencia de neumonía por Pneumocystis carinii asociada con el síndrome de inmunodeficiencia adquirida (SIDA).

Desde el inicio de la epidemia de infección por el virus de inmunode ficiencia humana (VIH), la neumonía por Pneumocystis carinii ha constituido la infección oportunista más frecuente en la mayoría de países occidentales (1). Su elevada frecuencia y su gravedad, con elevada mortalidad asociada, han motivado intensos esfuerzos de investigación que han producido importantes avances en el conocimiento tanto de las car acterísticas del microor ganismo como de la enfermedad que produce.

A pesar de que la neumonía por Pneumocystis carinii (NPC) es una de las entidades patológicas más frecuentes entre los pacientes con infección por VIH seriamente inmunocomprometidos, muchos de los factor es asociados al desar rollo de dicha enfermedad no son todavía bien conocidos.

Presentamos brevemente una revisión clínico-epidemiológica de los casos de neumonía por P neumocystis Carinii en pacientes con infección por el virus de inmunodeficiencia humana (VIH), diagnosticados en el Hospital Ntra. Sra. de Candelaria de S/C de Tenerife desde 1 de enero de 1994 hasta el 30 de abril de 1998.

Se diagnosticaron un total de 70 casos de NPC en 64 pacientes con infección por el VIH con la siguiente distribución anual: 20 en 1994, 17 en 1995, 13 en 1996, 13 en 1997 y 7 en 1998 (primer cuatrimestre). En 48 pacientes $(68,6 \%)$ la NPC representó índice definitorio de SIDA (14 de ellos (20\%) sin infección por VIH previamente conocida). No se realizó fibrobroncoscopia y lavado broncoalveolar (FBC-BAL) en 17 casos $(24,1 \%)$ por diferentes motivos (falta de colaboración, dificultades técnicas). Se realizó diagnóstico microbiológico en 30 casos $(42,9 \%)$, 28 en BAL (2) y 2 en esputo (3), y presuntivo en 40 $(57,1 \%)$.

La distribución por sexos fue la 